\title{
Changes in bottlenose dolphin whistle parameters related to vessel presence, surface behaviour and group composition
}

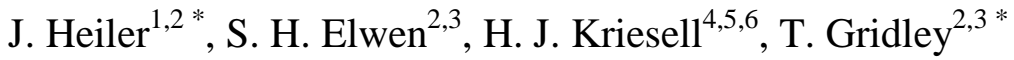

\footnotetext{
${ }^{1}$ Ghent University, Marine Biology Section, Gent, Belgium

${ }^{2}$ Sea Search Africa, Cape Town, South Africa

${ }^{3}$ Mammal Research Institute, Department of Zoology and Entomology, University of Pretoria, Gauteng, South Africa

${ }^{4}$ Centre Scientifique de Monaco, LIA-647 BioSensib, Monaco

${ }^{5}$ Université de Strasbourg, IPHC, Strasbourg, France

${ }^{6}$ CNRS UMR7178, Strasbourg, France

* Authors contributed equally to the preparation of this article.

Correspondence: J. Heiler, c/o Sea Search Africa, 4 Bath Road, Muizenberg, Cape Town, 7945, South Africa.

E-mail address: julia.heiler@web.de
}

\section{Highlights}

- Investigation of whale watching impact on acoustic behaviour of bottlenose dolphins.

- Dolphins shift whistles to higher frequency as short-term response to tour boat/s.

- The research vessel had less impact on whistle acoustic parameters.

- Important covariates for results are emotional arousal and group composition.

- Monitoring necessary to minimize long-term effects.

\begin{abstract}
Cetacean watching from tour boats has increased in recent years and has been promoted as an ethically viable alternative to cetacean viewing in captive facilities or directed take. However, short- and long-term impacts of this industry on the behaviour and energetic expenditure of cetaceans have been documented. Although multiple studies have investigated the acoustic
\end{abstract}


response of dolphins to marine tourism, there are several covariates that could also explain some of these results and should be considered simultaneously. Here, we investigated whether common bottlenose dolphins, Tursiops truncatus, inhabiting Walvis Bay, Namibia vary their whistle parameters in relation to boat presence, surface behaviour and/or group composition. We detected an upward shift of up to $1.99 \mathrm{kHz}$ in several whistle frequency parameters when dolphins were in the presence of one or more tour boats and the research vessel. No changes were demonstrated in the frequency range, number of inflection points or duration of whistles. A similar, although less pronounced difference was observed in response to engine noise generated by the research vessel when idling, suggesting that noise alone plays an important role in driving this shift in whistle frequency. Additionally, a strong effect of surface behaviour was observed, with the greatest difference in whistle parameters detected between resting and other behavioural states that are associated with higher degrees of emotional arousal. Group composition also contributed to the variation observed, with the impact of boats dependent on whether calves were present or not. Overall these results demonstrate high natural variation in the frequency parameters of whistles utilized by dolphins over varying behavioural states and group composition. Anthropogenic impact in the form of marine tour boats can influence the vocalization parameters of dolphins and such changes could have a long-term impact if they reduce the communication range of whistles or increase energy expenditure.

\section{Key words}

bottlenose dolphin, marine tourism, Namibia, Tursiops truncatus, vocal behaviour

Wildlife tourism involving cetacean (whale, dolphin and porpoise) watching has experienced rapid growth since the 1990s (Hoyt, 2001; O'Connor, Campbell, Cortez, \& Knowles, 2009). 
Globally, boat-based cetacean watching generates an estimated 2.2 billion US dollars annually (IWC, 2014). Revenue can provide a valuable subsidy to fishing communities and in some cases wild cetacean viewing has replaced direct hunting of whales and dolphins (Amir \& Jiddawi, 2001; Berggren et al., 2007). Compared with captive facilities, responsible boatbased cetacean watching has been promoted as an ethically acceptable option for observing dolphins, providing a valuable forum for environmental education and promotion of conservation efforts (IFAW, 1997). However, a considerable body of work has shown that boats and boat-based cetacean watching can have multiple negative impacts on the behaviour of the focal individual, population or species (Parsons, 2012). Short-term impacts associated with boat interactions include group directional changes (Steckenreuter, Möller, \& Harcourt, 2012; Stensland \& Berggren, 2007), changes in group dispersion (Arcangeli \& Crosti, 2009; Steckenreuter et al., 2012), heightened breathing synchrony (Hastie, Wilson, Tufft, \& Thompson, 2003), increased dive times (Lusseau, 2003b) and changes in vocalizations (Buckstaff, 2004; Scarpaci, Bigger, Corkeron, \& Nugegoda, 2000). Such changes can have longer lasting impacts resulting in seasonal (Rako et al., 2013) or long-term (Bejder et al., 2006) displacement and increased energy expenditure (Williams, Lusseau, \& Hammond, 2006).

Relative to observable changes in surface behaviour, the impacts of boats on the acoustic behaviour of cetaceans has received less attention. Changes in the production or parameters of vocalizations may be related to elevated levels of anthropogenic noise associated with vessel engines (Jensen et al., 2009; Parks, Johnson, Nowacek, \& Tyack, 2011; Pirotta et al., 2012), the physical presence of boats (Pirotta, Merchant, Thompson, Barton, \& Lusseau, 2015), boat type (La Manna, Manghi, Pavan, Lo Mascolo, \& Sarà, 2013) or vessel behaviour 
during encounters, and the interplay between these factors can be difficult to disentangle (see Ellison, Southall, Clarke, \& Frankel, 2011).

As cetaceans are highly acoustically oriented and rely on acoustic signals throughout their daily lives, they are particularly sensitive to elevated noise levels. Sound generated through outboard engines, which are typically used by small-scale cetacean watching boats, can be loud (149-152 $\mathrm{dB}$ re $1 \mu \mathrm{Pa}$ root mean square at $1 \mathrm{~m})$ and broadband, extending between 0.2 and $40 \mathrm{kHz}$ and result in significant reduction of communication range (Jensen et al., 2009). Although excessive noise can cause hearing damage, and even strandings in cetaceans (Weilgart, 2007), the more relevant impacts of boat noise generated through marine tourism activities are likely to be the masking of calls (Jensen et al., 2009) or biological cues (Clark et al., 2009), behavioural changes (Williams et al., 2006) or displacement (Rako et al., 2013), and stress (Rolland et al., 2012). Animals can adjust their acoustic signalling behaviour to respond to increases in noise in several different ways, which are not necessarily mutually exclusive. These are summarized by Radford, Kerridge, and Simpson (2014) as (1) avoidance of noise, by moving away from the noise source or adjusting the timing of acoustic signals to coincide with low noise periods, (2) adjustment of acoustic signal temporal parameters, such as increasing call duration or rate, (3) amplitude shifts, such as the 'Lombard effect' whereby animals produce higher amplitude acoustic signals in noise (Lombard, 1911), (4) frequency shifts in acoustic signals or the relative amplitude of signal components and (5) shifting emphasis to an alternative signal modality, for example by increasing the use of visual or chemical signals. Cetaceans are known to respond to boat noise sources in the first four ways (Ansmann, Goold, Evans, Simmonds, \& Keith, 2007; Foote, Osborne, \& Hoelzel, 2004; Holt, Noren, Veirs, Emmons, \& Veirs, 2009; Parks, Clark, \& Tyack, 2007; Parks et al., 2011; Rako 
et al., 2013) and may also increase their use of visual cues in elevated noise conditions (point 5 above, see Dunlop, Cato, \& Noad, 2010).

In bottlenose dolphins (Tursiops spp.) long-range communication relies on whistles, defined as narrow-band, frequency-modulated signals, ranging between 0.8 and $28.5 \mathrm{kHz}$ in frequency (May-Collado \& Wartzok, 2008; Schultz \& Corkeron, 1994). In favourable conditions, these signals can propagate over tens of kilometres (Janik, 2000). Whistle production is usually higher during socializing contexts (Jones \& Sayigh, 2002; Quick \& Janik, 2008) and when animals experience stress (Esch, Sayigh, Blum, \& Wells, 2009). Each bottlenose dolphin uses an individually distinctive signature whistle which is acquired through vocal production learning in the first year of life (Caldwell \& Caldwell, 1979; Janik \& Slater, 1997). Around 50\% of all whistles recorded from free-ranging bottlenose dolphins are signature whistles (Cook, Sayigh, Blum, \& Wells, 2004) which are used to convey identity information (Janik, Sayigh, \& Wells, 2006), facilitate group contact (Janik \& Slater, 1998; Quick \& Janik, 2012) and address conspecifics (King \& Janik, 2013). The function of other, nonsignature whistles in the dolphin's repertoire is less well understood. Nonsignature whistles may include shared whistle types (King \& Janik, 2015), copies of conspecifics' signature whistles (King, Sayigh, Wells, Fellner, \& Janik, 2013; Tyack, 1986; Watwood, Owen, Tyack, \& Wells, 2005) and nonstereotyped whistles produced by calves (Caldwell \& Caldwell, 1979).

Although several studies have investigated the likely impact of boat presence on dolphin communication signals including whistles (Buckstaff, 2004; May-Collado \& QuiñonesLebrón, 2014; Scarpaci et al., 2000), few have controlled for other key covariates that may influence whistle parameters such as behavioural context (Lemon, Lynch, Cato, \& Harcourt, 
2006; May-Collado \& Quiñones-Lebrón, 2014; Scarpaci et al., 2000). Furthermore, although variation in acoustic parameters can relate to behavioural state (Azevedo et al., 2010; MayCollado, 2013) and may be useful in predicting surface behaviour (Henderson, Hildebrand, \& Smith, 2011; Henderson, Hildebrand, Smith, \& Falcone, 2012; Hernandez, Solangi, \& Kuczaj, 2010) the available information poorly explains the causative factors of this variability. Esch, Sayigh, Blum, et al.'s (2009) study is the notable exception in detailing the influence of stress on whistle parameters and production rates. This contrasts with a wealth of comparative behavioural literature detailing consistent patterns in vocal parameters associated with varying levels of emotional arousal. In reviewing the available mammalian literature, Briefer (2012) highlighted strong evidence that heightened emotional arousal is associated with an increase in fundamental frequency (F0), F0 range, energy distribution and peak frequency, as well as increases in amplitude and vocalization rate. Vocalization or element duration may also increase with arousal, although this pattern is less consistent across species (Briefer, 2012).

Here we investigated variation in the acoustic parameters of whistle vocalizations of bottlenose dolphins in relation to key covariates: tour boat presence, surface behaviour and group composition. We also investigated the influence of engine noise generated by the research vessel as a possible source of disturbance. The study population in Walvis Bay, Namibia is the only inshore population of common bottlenose dolphins, Tursiops truncatus, inhabiting the southern African coastline (Best, 2007). This population is small, numbering around 100 individuals (Elwen, Snyman, \& Leeney, 2011), and is the focus of an intensive boat-based cetacean-watching industry involving approximately 23 motorized boats and generating an annual income of around 2.5 million US dollars per annum (Leeney, 2014). Quantifying the influence of tour boats on dolphins is necessary for effective management of 
cetacean populations in Namibian coastal waters. Previous research in the area by Indurkhya (2012) has shown a change in group surface behaviour during tour boat presence with dolphins decreasing their time spent resting and increasing time spent travelling and socializing. The duration of behavioural bout length (measured as the average length of time dolphins are continuously engaged in one of a predetermined number of key behavioural states, as defined below) also decreases when tour boats are present, indicating agitation during tour boat presence (Indurkhya, 2012). The frequency of engine noise produced by these tour boats has the potential to overlap the frequency of whistles produced by bottlenose dolphins in Walvis Bay (Gridley, Nastasi, Kriesell, \& Elwen, 2015). Short-term changes in the acoustic behaviour of this population relative to tour boat presence could indicate a human impact which should be properly managed to mitigate any potential long-term, negative effects on this small population of dolphins.

\section{METHODS}

Data were collected during five field seasons between 2009 and 2014 (see Table 1) in Walvis Bay $\left(22^{\circ} 57^{\prime} \mathrm{S}, 14^{\circ} 30^{\prime} \mathrm{E}\right)$, central Namibia. The north-facing bay is shallow (mostly $<15 \mathrm{~m}$ deep) with a muddy/sandy bottom and approximately $10 \times 10 \mathrm{~km}$ in area. The Walvis Bay bottlenose dolphin population is apparently isolated from other bottlenose dolphin populations along the west coast of Africa (Best, 2007; Findlay, Best, Ross, \& Cockcroft, 1992). Walvis Bay is the only embayment of significant size along the Namibian coastline and represents the core habitat for this population, as it provides shelter from strong southwesterly swells as well as good resting and foraging opportunities. 
Table 1: Vessels and equipment utilized for acoustic data collection between 2009 and 2014

\begin{tabular}{lll}
\hline \hline Data collection & Research vessel & Recording device \\
\hline \hline February-March 2009 & 8 m ski boat fitted with twin 80hp 4- & Edirol UA-25 sound card to \\
& stroke Honda engines & PC \\
June-August 2011 & 5.7 m rigid hulled inflatable boat & Zoom H4n digital recorder \\
& (RHIB) fitted with twin 50 hp 2- & \\
June-August 2012, & stroke Mercury engines & Zoom H4n digital recorder \\
January and June 2013 & 5.7 m rigid hulled inflatable boat & \\
and January 2014 & (RHIB) fitted with twin 60 hp 4- & \\
& stroke Yamaha engines & \\
\hline
\end{tabular}

Local weather conditions create calm and flat seas in the bay during the morning with stronger winds in the afternoons (usually Beaufort 4 or higher). Therefore, boat surveys to conduct focal follows (Altmann, 1974) of groups were mostly carried out in the mornings when the probability of finding dolphins was highest. When dolphins were sighted, an encounter began and acoustic data were collected. Each encounter started with a concentrated period of photo-identification to determine the individuals present and photography continued throughout encounters whenever possible. Standard information on the estimated group size, dispersion and number of calves was documented at the start and end of each encounter. No focal follow lasted more than $4 \mathrm{~h}$ and most $(86 \%)$ lasted between 1 and $2.5 \mathrm{~h}$.

Data on group surface behaviour and tour boat presence were point sampled every 3 min during encounters, allowing 1 min to observe and assign the behaviours. Tour boats were deemed present (TB-P) during a point sample if one or more were located within $200 \mathrm{~m}$ of the focal group. If further than 200 m away, tour boats were considered absent from the point sample (TB-A). Most tour boats in Walvis Bay operate with four-stroke outboard or inboard diesel motors with varying travel speeds. The behaviour of dolphins encountered was 
Table 2: Behavioural state categories based on Lusseau (2003a) to describe the repertoire of behaviours observed

\begin{tabular}{|c|c|c|}
\hline Behaviour & & Definition \\
\hline Resting & $\mathrm{R}$ & $\begin{array}{l}\text { Slow, directed movement (slower than idle speed of vessel); no splashing; } \\
\text { closely grouped or in subgroups; short, relatively constant, synchronous dive } \\
\text { intervals }\end{array}$ \\
\hline Travelling & TR & $\begin{array}{l}\text { Steady movement in a constant direction; short, relatively consistent dive } \\
\text { intervals; often much splashing }\end{array}$ \\
\hline Milling & M & $\begin{array}{l}\text { No net movement; individuals surfacing facing different directions; pod often } \\
\text { changes direction; dive intervals vary. May indicate a transitory phase } \\
\text { between other more functional behaviours like foraging or socializing }\end{array}$ \\
\hline Surface feeding & SF & $\begin{array}{l}\text { Animals usually dispersed; frequent direction changes; fish chases at the } \\
\text { surface; seals and birds often in attendance }\end{array}$ \\
\hline Socializing & SOC & $\begin{array}{l}\text { Diverse interactive behavioural events; jumps, chases, body contact; no } \\
\text { directed movements; dive intervals vary }\end{array}$ \\
\hline
\end{tabular}

Behavioural state was assessed through point sampling every 3 min. A sixth category (submerged) was used if all animals in the focal group remained underwater and were not seen during the allocated point sampling period (first minute of every 3 min period).

assessed using a focal group sampling method whereby we assigned the predominant group behaviour for the majority ( $>50 \%$ ) of the group to a predetermined set of behavioural states (Mann, 1999). Where appropriate, we assigned the behaviour of the remaining group to a secondary behavioural category. This approach was also used if dolphins were split into subgroups, or if a small proportion of the group was engaged in an obviously different behaviour (e.g. a subgroup milling while the majority of the group socialized). Behavioural states were classified as resting (R), milling (M), travelling (TR), socializing (SOC) and surface feeding (SF) based on Lusseau (2003a; Table 2) and were designed to be mutually 
exclusive but together describe the entire observable behavioural budget of the population. Group composition data were taken from the information recorded at the start and end of each encounter and encounters were rated as calves present (C-P) or calves absent (C-A).

As far as possible, underwater acoustic recordings of dolphin vocalizations were made while standing off the dolphin group at a distance of 50 to $200 \mathrm{~m}$, using the equipment reported in Table 1. Throughout the study we used a single-element High-Tec HTI-96-MIN hydrophone with a frequency response of $2 \mathrm{~Hz}$ to $30 \mathrm{kHz}( \pm 1 \mathrm{~dB})$. The recorders used (Table 1) sampled the data at $96 \mathrm{kHz}$. The hydrophone was weighted using a $1 \mathrm{~cm}$ diameter steel chain and lowered 2-3 m below the surface of the water. When dolphins were found in waters $<3.5 \mathrm{~m}$ deep, the hydrophone depth was reduced accordingly. Whenever possible, acoustic recordings were made when the research vessel was stationary, idling or travelling slowly (less than 8 knots). However, in some encounters recordings could not be made, were interrupted or terminated. This happened, for example, when dolphins were positioned in the surf zone where engines could not safely be switched off, with groups moving into very shallow waters or when groups were travelling fast.

\section{Acoustic and Behavioural Analysis}

Our analysis focuses on acoustic parameters of bottlenose dolphins encountered in Walvis Bay. Sound types were identified in the spectrogram display of Adobe Audition CS5.5 (version 4.0, Adobe Systems Inc., San Jose, CA, U.S.A.), and Raven Pro 1.4 (http://www.birds.cornell.edu/brp/raven/ravenversions.html ) by visually and aurally scanning the recordings. The spectrogram display was created using a Hanning window with an FFT of 512 for whistle identification. Whistles were defined as narrow-band tonal signals longer than $0.1 \mathrm{~s}$ in duration (Janik, King, Sayigh, \& Wells, 2013; Lilly \& Miller, 1961). We 
included only those for which at least part of the fundamental frequency was above $3 \mathrm{kHz}$ (Gridley, Berggren, Cockcroft, \& Janik, 2012). This distinguishes whistles from other narrow-band sounds produced by bottlenose dolphins (Simard et al., 2011; van der Woude, 2009). Whistles interrupted by very short breaks $(<0.03 \mathrm{~s})$ were considered as continuous, but no attempt was made to identify disconnected multiloops (Esch, Sayigh, \& Wells, 2009; Janik et al., 2013) or signature whistles (Caldwell, Caldwell, \& Tyack, 1990). Signature whistles in this population are described elsewhere (Kriesell, Elwen, Nastasi, \& Gridley, 2014).

Low-frequency vessel noise can mask the low-frequency components of whistles, resulting in an apparent shift in frequency during spectrographic analysis and subsequent measurement error. To avoid this issue, we carefully filtered our data so that only high-quality whistles, with the entire contour clearly visible, were measured, even during periods with background vessel noise. This was achieved through visual assessment and grading of each whistle contour, based on the signal-to-noise ratio (SNR) as follows: 1: signal is faint but visible on the spectrogram; 2: signal is clear and unambiguous; 3 : signal is prominent and dominates. High-quality whistles were those, assessed as SNR 2 or 3, which had a clear start/end and were not masked by simultaneous sound. For each high-quality whistle identified, a number of acoustic parameters were measured. The duration and number of inflection points (i.e. change in slope from positive to negative or vice versa) were assessed from visual inspection of the spectrogram in Adobe Audition. Minimum and maximum frequency were automatically measured with the selection function in the spectrogram view of Raven Pro (setting Hanning window with FFT of 512, brightness 70, contrast 50) and frequency range was calculated as the difference between these values. Whistle start and end frequency were measured manually in Raven. For each whistle analysed, we assessed whether concurrent 
boat engine noise was present or absent. If present, we determined whether the noise was generated from the research vessel (RV) engine/s or from one or more tour boats, or both noise sources combined. This was achieved through careful visual and aural inspection of the acoustic file. We also noted the maximum frequency of this engine noise concurrent with the measured whistle.

Each whistle contour was assigned a matching tour boat condition (TB-P or TB-A), group behavioural state (R/M/TR/SOC/SF/SUB) and calf presence (C-P or C-A) based on the following decision rule applied to the field observation data. The real start time of each analysed whistle from the acoustic files was calculated and compared to the time of each behavioural point sample. A whistle was paired with a behavioural point sample, the associated group composition and tour boat presence data, when the whistle start time occurred $1 \mathrm{~min}$ before the point sample or $1 \mathrm{~min} 59 \mathrm{~s}$ after the point sample. Whistles paired with a point sample in which information was missing from the field observations were excluded from any further analysis. To account for the secondary behavioural states involving milling, which may indicate a transition between states (Quick \& Janik, 2008), a mixed behavioural state (MIX) was introduced at the analysis stage. It was assigned to point samples where milling behaviour was documented as the primary behaviour with either socializing or surface feeding as the secondary behaviour, or in cases where socializing or surface feeding was the primary behaviour with milling as the secondary behaviour. If milling was the primary behaviour observed, without any secondary behaviour noted, this classification was left unchanged as milling. Other combinations of primary and secondary behaviours occurred infrequently and whistles produced during these times were therefore excluded from the analysis. 


\section{Statistical Analysis}

\section{Influence of tour boat presence and engine noise}

We conducted univariate statistical analyses to determine the influence of tour boat presence and engine noise on dolphin whistle parameters. Analysis was performed in R (version 3.1.1, The R Foundation for Statistical Computing, Vienna, Austria, http://www.r-project.org) using the RStudio interface (version 0.98.1103 ). Visual classification via QQ-plots and histograms showed that the acoustic parameters were not normally distributed. The influence of tour boat presence on each of the seven parameters of dolphin whistles was therefore tested using nonparametric ANOVAs (Mann-Whitney $U$ tests). Bonferroni correction was applied to the $\alpha$ value, i.e. $\alpha$ after Bonferroni correction $=0.05 / 7$ comparisons $=0.007$. This analysis assumed that our research vessel was a constant under both the TB-A and TB-P conditions and that any effect could be caused by engine noise or the physical presence of one or more boats. As the research vessel was always present, whistle parameters in the absence of boats could not be tested. Also, owing to restrictions of sample size, we were not able to investigate the influence of number of tour boats on dolphin whistle parameters.

To investigate the effect of elevated levels of engine noise on whistle parameters, we used data from when tour boats were absent and only the research vessel was present. We compared the parameters of whistles recorded when the research vessel engines were off (RV-OFF) to when one or both were on and idling but not in gear (RV-ON). Under both conditions the research vessel was stationary and no other boats were interacting with the focal group; therefore boat presence was a constant in this analysis. Parameter differences were compared using nonparametric ANOVAs (Mann-Whitney $U$ tests) with a Bonferroni correction applied as above. 


\section{Influence of tour boats, surface behaviour and calves}

We extended our analysis to investigate the influence of surface behaviour and group composition (calf presence) in addition to tour boat presence on each of the seven whistle parameters using a generalized linear model (GLM) approach. Within each of the seven models generated, explanatory covariables were included as categorical variables. After rejection of collinearity, the four possible predictors in each full model were (1) tour boat presence, (2) surface behaviour and (3) calf presence and (4) the interaction between tour boat presence and calf presence. Sample size restriction prevented the influence of other interactions from being investigated. We applied a GLM with a gamma distributed error structure for the six response variables other than number of inflection points, as this describes right-skewed continuous positive data better than a normal distribution (Crawley, 2007). The count of inflection points was modelled as a discrete variable and, after detecting overdispersion, the error structure was corrected by fitting a quasi-Poisson GLM. The appropriateness and assumptions for each model were checked visually by assessment of model diagnostics in R. Only the best fitting predictors, chosen via the corrected Akaike information criterion (AICc) value, were included in the final model for each parameter. Analysis of Variance type II (function 'Anova' in the 'car' library in R) was used to assess the significance of the predictors (Langsrud, 2003). Tukey contrasts as post hoc tests were calculated from the fitted model to conduct pairwise comparisons between levels of predictors (function 'glht' in 'multcomp' library in R).

\section{Ethical Note}

Ethics clearance for this study was obtained from the University of Pretoria's Animal Use and Care Committee under the permit number EC061 and EC020. Research in Namibia was conducted with permission from the Namibian Ministry of Fisheries and Marine Resources 
(no specific permit required). The study was entirely observational and care was taken when approaching animals.

\section{RESULTS}

Between 2009 and 2014 we made acoustic recordings during 69 encounters with bottlenose dolphins in coastal Namibia. All recordings were made in or around Walvis Bay, apart from one ( $N=22$ whistles analysed) made during an encounter in Lüderitz with known individuals from the Walvis Bay population, identified photographically. In total, more than $79 \mathrm{~h}$ of acoustic data were collected over varying behavioural states and group compositions.

A total of 3837 whistles were identified from acoustic recordings. After visual assessment of SNR, 828 whistles were considered of high enough quality to be measured and analysed. These whistles were recorded over 36 different encounters on 35 fieldwork days. The vast majority of these whistles $(92 \%, N=765)$ were recorded when the minimum distance to the focal group was $\leq 150 \mathrm{~m}$. One to four $(\bar{X} \pm \mathrm{SD}=1.5 \pm 0.7)$ tour boats were present during 10 of the 36 encounters from which whistles were analysed. Overall, 17\% $(N=137)$ of whistles analysed were associated with the presence of one or more tour boats and $83 \%(N=691)$ were recorded when tour boats were absent. Best estimates for group sizes during encounters from which whistles were analysed ranged between two and 50 individuals $(\bar{X} \pm \mathrm{SD}=15 \pm 12)$. Groups including calves were slightly larger ranging from seven to 50 animals than groups without calves $(\bar{X}$ group size $\mathrm{C}-\mathrm{A}=9, \bar{X}$ group size $\mathrm{C}-\mathrm{P}=21)$. Fiftyseven per cent $(N=471)$ of the analysed whistles were recorded when calves were present in the focal group. 


\section{Influence of tour boat presence and engine noise}

There was a net upward shift in whistle frequency when one or more tour boats were in the vicinity of focal groups. Dolphins vocalized with significantly higher minimum, maximum, start and end frequency in the presence of one or more tour boats (Fig. 1, Table 3). Frequency range, however, did not differ between TB-P and TB-A conditions, nor was there a significant change in whistle duration or the number of inflection points (Fig. 1, Table 3). The greatest shift in frequency was observed for start frequency $(1.99 \mathrm{kHz})$ and the least for minimum frequency $(1.08 \mathrm{kHz}$; Table 3$)$.

A visual assessment of the analysed whistle contours recorded under the TB-P conditions when the research vessel engine was off revealed that $30 \%(N=27)$ of analysed whistles were recorded when low-frequency noise attributed to one or more tour boats was under $4 \mathrm{kHz}, 54 \%(N=49)$ when this noise extended up to $4-6 \mathrm{kHz}$ and $16 \%(N=15)$ when it extended up to 6 - $9 \mathrm{kHz}$. Occasionally more broadband noise was apparent, either associated with gear shifts or during approach and departure of tour boats, when vessel speeds were greatest.

When tour boats were absent, the noise of the idling research vessel engine had a maximum frequency of $4-6 \mathrm{kHz}$ and was generally quiet $(\bar{X}$ of 10 measurements $\pm \mathrm{SD}=20.4 \pm 5.3 \mathrm{~dB}$, above ambient noise levels) compared to the acoustic signals of bottlenose dolphins in the vicinity. This engine noise had a moderate influence on whistle parameters, with end and minimum frequency shifting significantly upwards by $1.19 \mathrm{kHz}$ and $0.7 \mathrm{kHz}$, respectively, between RV-OFF $(N=566)$ and RV-ON $(N=125)$ conditions (Table 3$)$. No difference was observed for any of the other five remaining parameters measured (Table 3). These results suggest that (1) engine noise alone influences whistle parameters and (2) that the influence of 

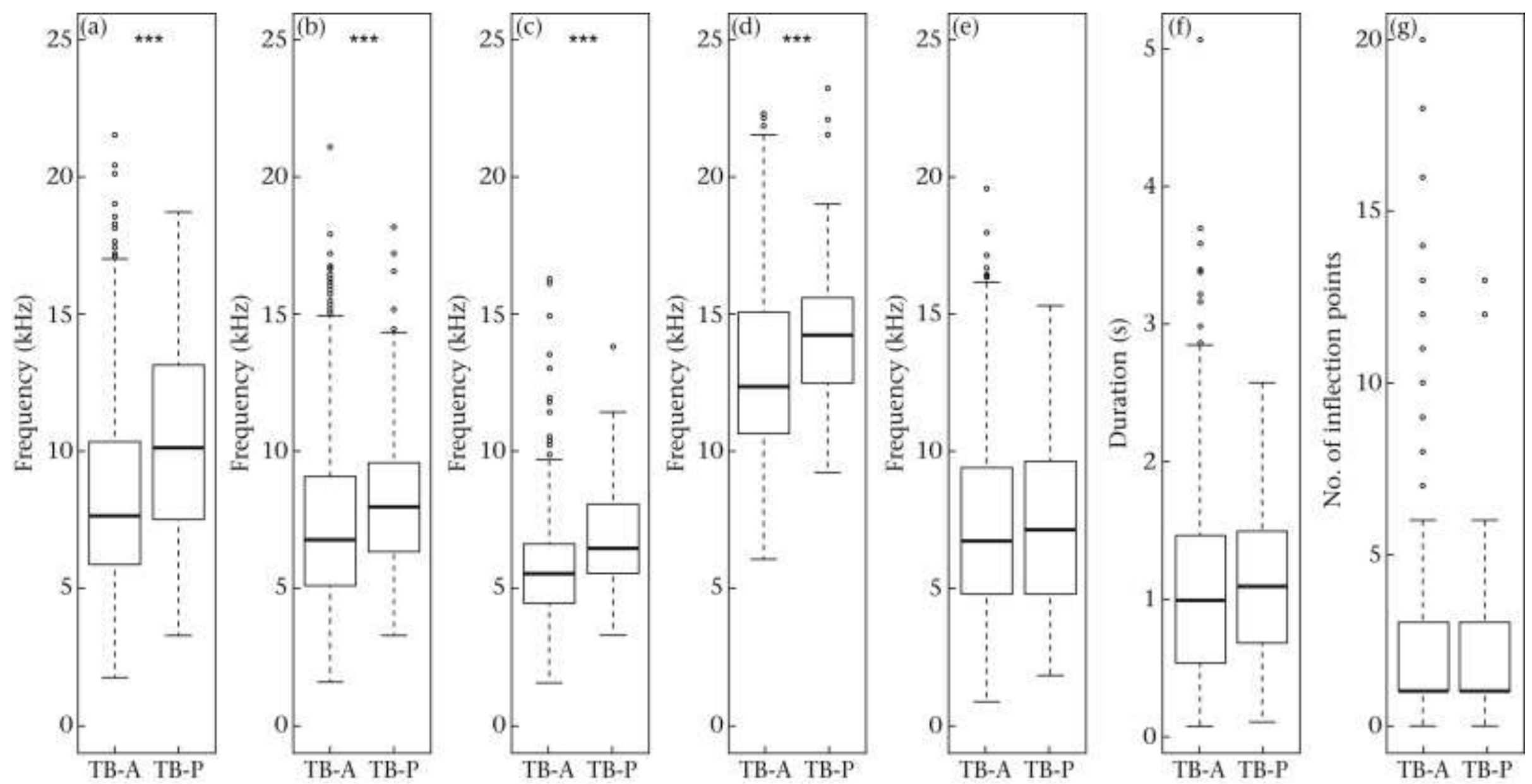

Figure 1: Distribution of (a) start frequency, (b) end frequency, (c) minimum frequency, (d) maximum frequency, (e) frequency range, (f) whistle duration and (g) inflection points, with one or more tour boats present (TB-P) and absent (TB-A). The horizontal line in the box represents the median; the bottom and the top of the box are the first and third quartiles. Whiskers show values within 1.5 times of the interquartile range from the boxes and outliers are plotted as single points. Asterisks (***) mark parameters with highly significant differences between tour boat presence and absence after Bonferroni correction was applied $(P<0.001 / 7)$. 
Table 3: Comparison of the acoustic parameters from whistles of common bottlenose dolphins from Walvis Bay, Namibia

\begin{tabular}{|c|c|c|c|c|c|c|c|c|c|}
\hline \multirow[t]{4}{*}{ Acoustic parameter } & \multirow{3}{*}{$\begin{array}{l}\text { Overall } \\
\bar{X} \pm \mathrm{SD}(\mathrm{CV})\end{array}$} & \multicolumn{4}{|c|}{ Effect of tour boat(s) } & \multicolumn{4}{|c|}{ Effect of research vessel engine } \\
\hline & & TB-A & TB-P & Test statistic & $P$ & RV-OFF & $\mathrm{RV}-\mathrm{ON}$ & Test statistic & $P$ \\
\hline & & $\bar{X} \pm \mathrm{SD}(\mathrm{CV})$ & $\bar{X} \pm \mathrm{SD}(\mathrm{CV})$ & & & $\bar{X} \pm \mathrm{SD}(\mathrm{CV})$ & $\bar{X} \pm \mathrm{SD}(\mathrm{CV})$ & & \\
\hline & $N=828$ & $N=691$ & $N=137$ & & & $N=566$ & $N=125$ & & \\
\hline Start frequency $(\mathrm{kHz})$ & $8.73 \pm 3.51(40)$ & $8.40 \pm 3.42(41)$ & $\begin{array}{l}10.38 \pm 3.50 \\
(34)\end{array}$ & $U=31367$ & $<0.001$ & $8.33 \pm 3.43(41)$ & $8.70 \pm 3.36(39)$ & $U=32839.5$ & 0.210 \\
\hline End frequency $(\mathrm{kHz})$ & $7.41 \pm 3.13(42)$ & $7.23 \pm 3.14(43)$ & $8.31 \pm 2.95(35)$ & $U=36747.5$ & $<0.001$ & $7.02 \pm 3.21(46)$ & $8.21 \pm 2.59(32)$ & $U=25247.5$ & $<0.001$ \\
\hline Minimum frequency (kHz) & $5.80 \pm 1.92(33)$ & $5.61 \pm 1.89(34)$ & $6.75 \pm 1.83(27)$ & $U=30600.5$ & $<0.001$ & $5.49 \pm 1.96(36)$ & $6.19 \pm 1.37(22)$ & $U=25405.5$ & $<0.001$ \\
\hline Maximum frequency $(\mathrm{kHz})$ & $\begin{array}{l}13.18 \pm 3.04 \\
\text { (23) }\end{array}$ & $\begin{array}{l}12.99 \pm 3.10 \\
(24)\end{array}$ & $\begin{array}{l}14.12 \pm 2.57 \\
(18)\end{array}$ & $U=35569.5$ & $<0.001$ & $\begin{array}{l}12.94 \pm 3.19 \\
(25)\end{array}$ & $\begin{array}{l}13.12 \pm 2.62 \\
(20)\end{array}$ & $U=32301$ & 0.128 \\
\hline Frequency range $(\mathrm{kHz})$ & $7.38 \pm 3.45(47)$ & $7.38 \pm 3.55(48)$ & $7.37 \pm 2.87(39)$ & $U=46034$ & 0.612 & $7.46 \pm 3.62(49)$ & $7.02 \pm 3.23(46)$ & $U=37229$ & 0.359 \\
\hline Duration (s) & $1.08 \pm 0.65(60)$ & $1.07 \pm 0.67(63)$ & $1.13 \pm 0.55(49)$ & $U=42845$ & 0.079 & $1.08 \pm 0.67(62)$ & $1.01 \pm 0.69(68)$ & $U=37990$ & 0.196 \\
\hline Number of Inflection points & $\begin{array}{l}1.96 \pm 2.15 \\
(109)\end{array}$ & $\begin{array}{l}1.79 \pm 2.15 \\
(120)\end{array}$ & $\begin{array}{l}1.92 \pm 2.12 \\
(110)\end{array}$ & $U=47924.5$ & 0.809 & $\begin{array}{l}2.02 \pm 2.17 \\
(107)\end{array}$ & $\begin{array}{l}1.76 \pm 2.03 \\
(115)\end{array}$ & $U=37459$ & 0.279 \\
\hline
\end{tabular}

Means \pm SD and Mann-Whitney $U$ test statistic with $P$ value for testing the effect between one or more tour boats present (TB-P) and absent (TB-A) as well as testing the effect of the research vessel with one or more tour boats absent and the engine of the research vessel on (RV-ON) compared to off (RV-OFF). The coefficient of variation (CV) is displayed in parentheses. 
boats (assessed by the number of parameters affected) increases when more boats are present and/or boats are moving in the vicinity of animals (Fig. 1, Table 3).

\section{Multivariate analysis}

Table 4 details the variables included in each model after model selection, along with a summary of the model outcomes. Results from the GLM analysis support the simpler univariate ANOVA results, showing that tour boat presence is associated with a net upwards frequency shift in whistle vocalizations for all frequency parameters measured, without any detectable change to frequency range. Model selection indicated that the presence of one or more tour boats was not a significant contributor to models describing the influence on whistle duration or number of inflection points.

Surface behaviour was identified as an important covariable significantly influencing all acoustic parameters measured. Post hoc tests (Fig. 2) identified the largest differences between resting and surface feeding, resting and socializing and, to a lesser degree, between resting and travelling. Start, end and minimum frequency were lower during resting $(\bar{X}=7.27 \mathrm{kHz}, 6.10 \mathrm{kHz}$ and $4.82 \mathrm{kHz}$, respectively) than during surface feeding $(\bar{X}=9.52 \mathrm{kHz}, 7.50 \mathrm{kHz}$ and $5.99 \mathrm{kHz}$, respectively, $\operatorname{glm} P<0.001$ for start and minimum frequency, $P=0.008$ for end frequency). Maximum frequency was $1.29 \mathrm{kHz}$ higher during resting than surface feeding ( $\operatorname{glm} P=0.029)$. As a result, frequency range also differed between these behavioural states $(\bar{X}$ frequency range during resting $=9.25 \mathrm{kHz} ; \bar{X}$ frequency range during surface feeding $=6.53 \mathrm{kHz}$ ). Similar patterns were detected for socializing: start

and minimum frequency were lower during resting $(\bar{X}=7.27 \mathrm{kHz}$ and $4.82 \mathrm{kHz}$, respectively) than socializing $(\bar{X}=8.84 \mathrm{kHz}$ and $5.50 \mathrm{kHz}$, respectively, $\operatorname{glm} P=0.02$ for start frequency and $P=0.011$ for minimum frequency). Although not significant, maximum frequency was 

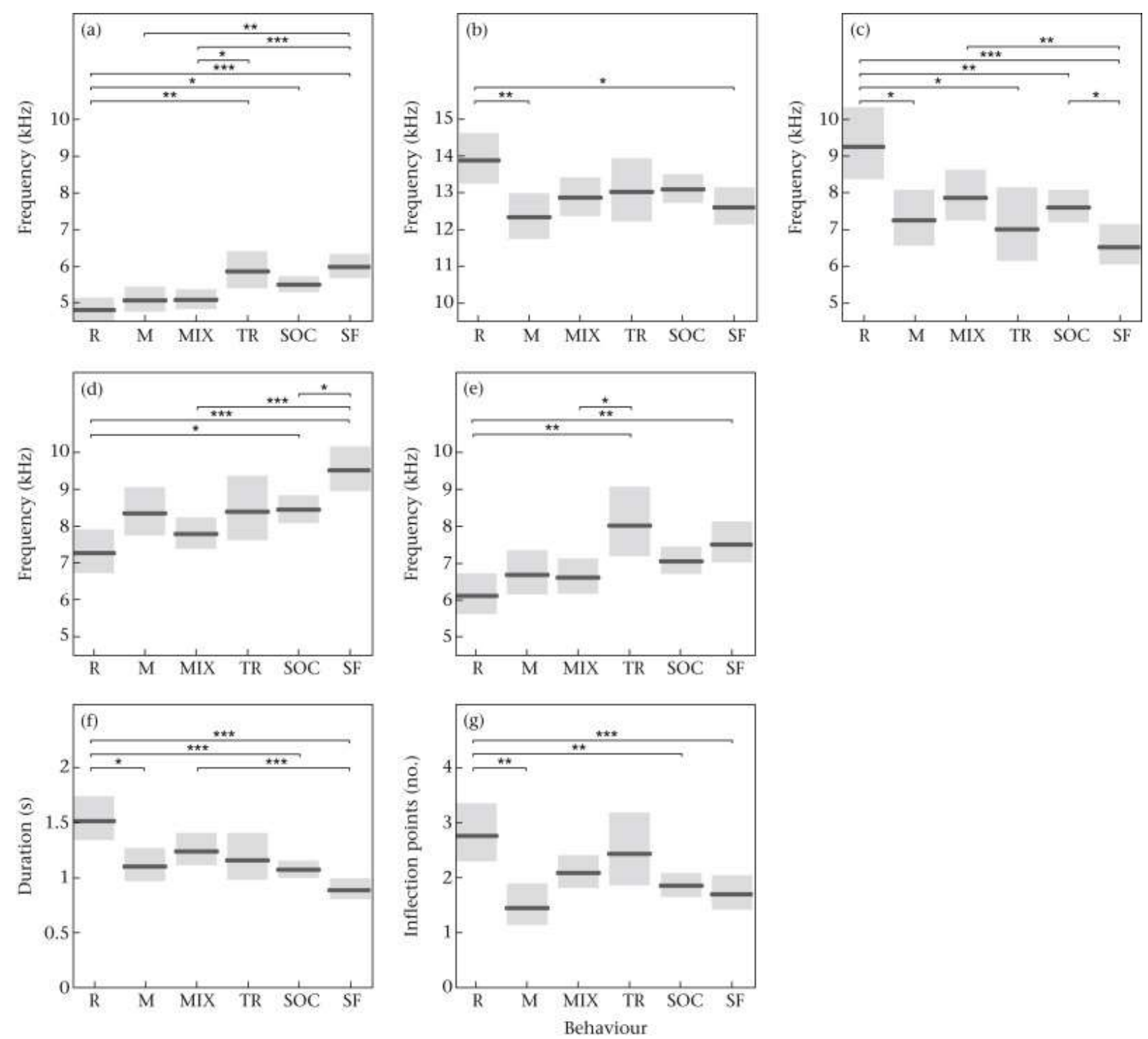

Figure 2: Changes in (a) minimum frequency, (b) maximum frequency, (c) frequency range, (d) start frequency, (e) end frequency, (f) duration and (g) inflection points for surface behaviour as a predictor in the model. Black lines show the fitted value, grey boxes represent upper and lower confidence intervals (95\%); lines and asterisks above the plot indicate significant differences between behavioural states: $\mathrm{R}=$ resting, $\mathrm{M}=\mathrm{milling}$, $\mathrm{MIX}=$ mixed behaviour, $\mathrm{TR}=$ travelling, $\mathrm{SOC}=$ socializing, $\mathrm{SF}=$ surface feeding. $* P \leq 0.05 ; * * P<0.01$; $* * * P<0.001$. 
higher during resting $(\bar{X}=13.89 \mathrm{kHz})$ than during socializing $(\bar{X}=13.10 \mathrm{kHz})$, and in turn the frequency range of whistles recorded during resting was significantly greater than for whistles identified from socializing contexts ( $\operatorname{glm} P=0.008)$. The comparisons between resting and travelling followed a similar trend with end and minimum frequency of whistles lower during resting $(\bar{X}=6.11 \mathrm{kHz}$ and $4.82 \mathrm{kHz}$, respectively) than travelling $(\bar{X}=8.01 \mathrm{kHz}$ and $5.86 \mathrm{kHz}$, respectively, glm $P=0.02$ for end frequency and $P=0.003$ for minimum frequency), and again a significant increase in the frequency range was observed between these behavioural states $(\mathrm{g} \operatorname{lm} P=0.03)$.

Models investigating the effect of behaviour on the number of inflection points and whistle duration also indicated a difference between resting and other behaviours. Most notably, whistles had more inflection points and were significantly longer during resting $(\bar{X}=2.77$ and $1.51 \mathrm{~s}$, respectively) than surface feeding $(\bar{X}=1.42$ and $0.89 \mathrm{~s}$, respectively) or socializing $(\bar{X}=1.64$ and $1.07 \mathrm{~s}$, respectively). Combined, these results indicate a systematic difference in whistle frequency, modulation and duration between resting and behavioural states associated with a higher degree of emotional arousal such as socializing and surface feeding.

The presence of calves in groups had a mixed effect on whistle parameters and was also influenced by the presence of one or more tour boats. Model results indicated that when calves were present, end frequency and minimum frequency were lower whereas whistle duration was longer (Table 4). Model selection also indicated a significant interaction between tour boat presence and calf presence for maximum frequency and frequency range (Table 4). When calves were present, whistle maximum frequency varied little with tour boat presence. However, when calves were absent, maximum frequency was significantly higher in the presence of tour boats $(\bar{X}$ difference between $\mathrm{C}-\mathrm{A}+\mathrm{TB}-\mathrm{A}$ versus $\mathrm{C}-\mathrm{A}+\mathrm{TB}-$ 
Table 4: Summary of the best fitting model for each acoustic parameter

\begin{tabular}{|c|c|c|c|c|}
\hline Acoustic parameter & $\begin{array}{l}\text { Tour boat } \\
\text { presence }\end{array}$ & $\begin{array}{l}\text { Surface } \\
\text { behaviour }\end{array}$ & Calf presence & $\begin{array}{l}\text { Tour boat/Calf } \\
\text { interaction }\end{array}$ \\
\hline Start frequency & $\begin{array}{l}* * * \\
\uparrow\end{array}$ & *** & NA & NA \\
\hline End frequency & $\begin{array}{l}* * * \\
\uparrow\end{array}$ & $* * *$ & $\begin{array}{l}* \\
\downarrow\end{array}$ & NA \\
\hline Minimum frequency & $\begin{array}{l}* * * \\
\uparrow\end{array}$ & $* * *$ & $\begin{array}{l}* * \\
\downarrow\end{array}$ & NA \\
\hline Maximum frequency & $\begin{array}{l}* * * \\
\uparrow\end{array}$ & $*$ & - & $* * *$ \\
\hline Frequency range & - & $* * *$ & - & $* * *$ \\
\hline Duration & NA & $* * *$ & $\begin{array}{l}* \\
\uparrow\end{array}$ & NA \\
\hline Inflection points & NA & $* * *$ & NA & NA \\
\hline
\end{tabular}

Predictors with 'NA' were not included in the final model (predictor selection via AICc); asterisks show level of significance for contributing predictors $(* P \leq 0.05 ; * * P<0.01 ; * * * P<0.001)$ and a dash indicates a predictor retained in the final model but that did not have a significant effect (see text for details). Arrows indicate whether the predictor had a positive or negative effect on the acoustic parameter (applicable for binary variables only).

$\mathrm{P}=2.76 \mathrm{kHz}$ ). As frequency range is derived from the difference between maximum and minimum frequency, this effect was reflected in a significant increase in the frequency range of whistles in noncalf groups when tour boats were absent. Model results concerning this interaction term indicate that the effect of tour boats on certain whistle parameters is influenced by the presence of calves within groups. 


\section{DISCUSSION}

Acoustic communication in bottlenose dolphins relies on whistle vocalizations. Within the fission-fusion society in which dolphins exist, these signals are used to maintain group cohesion (Janik \& Slater, 1998), facilitate group joins (Quick \& Janik, 2012) and address conspecifics (King \& Janik, 2013). Whistles may also be used to share information on food patches (King \& Janik, 2015). This study suggests that the acoustic parameters of whistle vocalizations vary naturally according to behavioural context and group composition, but are also influenced by tour boat presence and engine noise. The vocalization changes we observed in the presence of one or more tour boats could have a long-term, negative influence on the bottlenose dolphin population in Walvis Bay if they reduce the communication range of whistles (Jensen et al., 2009), result in increased energy expenditure (Holt, Noren, Dunkin, \& Williams, 2015; Williams et al., 2006) or elevate stress levels (Rolland et al., 2012; Romano et al., 2004). Such effects would be compounded if combined with other behavioural responses to tour boat presence that increase energy expenditure, for example increased socializing or travelling (Indurkhya, 2012).

Our findings cannot be attributed to measurement error caused by masking from boat noise, as in this case we would expect a reduction in the frequency range, duration and possibly number of inflection points of whistles measured. No such reduction was detected. Whistle selection did not favour high-frequency whistles under the TB-P condition: there was no significant difference in the frequency minima of whistles analysed under TB-P conditions compared to those that were too poor quality (low SNR, masked) to be analysed fully ( $N$ $=250$ subsampled poor-quality whistles measured from TB-P condition, $U=17685$, $P=0.595)$. Whistles excluded had a lower maximum frequency $(U=9013, P<0.001)$, which might be expected due to propagation loss. Our results are therefore consistent with a 
short-term acoustic behavioural response, with animals shifting the frequency of their whistle vocalizations upwards when boats are close by. Although the $200 \mathrm{~m}$ radius we used to determine tour boat presence is lower than the $400 \mathrm{~m}$ radius used in some studies (Buckstaff, 2004; Lusseau, 2003a), it is somewhat greater than the criteria used in others (Christiansen, Lusseau, Stensland, \& Berggren, 2010). We consider our results to be conservative. If dolphins are perceiving the engine noise from tour boats at a distance greater than $200 \mathrm{~m}$, the shift in whistle frequency parameters we observed would be apparent in the TB-A data, and therefore reduce the overall significance of the effect reported. We observed similar but less pronounced frequency shifts in response to the research vessel engine, suggesting that some of the observed changes in whistles can be attributed to engine noise alone. When other covariates were taken into consideration, the group behavioural state had a clear influence on whistle parameters, with characteristics associated with resting behaviour different to those of higher emotional arousal. These results indicate the importance of considering several covariates when assessing human impacts on cetacean vocal behaviour.

The ultimate aim of most noise-induced vocal modification is to maintain the signal-to-noise ratio of calls during increased ambient noise (Hotchkin \& Parks, 2013). In species that display vocal plasticity, such as birds, bats and cetaceans, shifts in call frequency can help achieve this and geographical variation in these call parameters has been linked to natural variation in ambient noise levels from biotic and abiotic factors (Brumm \& Slabbekoorn, 2005; Foote \& Nystuen, 2008; Hage, Jiang, Berquist, Feng, \& Metzner, 2013; Mossbridge, Shedd, \& Thomas, 1999). Elevated anthropogenic noise levels may also promote these frequency shifts (Ansmann et al., 2007; Lesage, Barrette, Kingsley, \& Sjare, 1999; Luís, Couchinho, \& dos Santos, 2014; Morisaka, Shinohara, Nakahara, \& Akamatsu, 2005; Parks et al., 2007). The small motorized boats often involved in cetacean watching tend to generate 
most noise in the low- to mid-frequency ranges (Jensen et al., 2009; Lemon et al., 2006; Lesage et al., 1999) and several studies focused on cetacean vocal parameters have identified an upward frequency shift or increase in minimum or mean frequency associated with boat presence (Lesage et al., 1999; Luís et al., 2014; Parks et al., 2007). When viewing dolphins in close proximity $(<200 \mathrm{~m})$ the tour boats operating in Walvis Bay were usually stationed with idling engines or manoeuvring slowly. The associated engine noise generated, the frequency of which was measured when occurring concurrently with analysed whistles, was mostly under $6 \mathrm{kHz}$ but extended up to $9 \mathrm{kHz}$. Thus the frequency shift we observed (ranging on average between $1.08 \mathrm{kHz}$ and $1.99 \mathrm{kHz}$ depending on the parameter measured) may not shift the entire whistle contour above the masking noise generated by tour boat engines, but may reduce masking effects at times when boat noise is present but low and limited to the lower frequency ranges. An upward shift in whistle frequency adopted by dolphins may therefore help reduce vocal masking by tour boat engine noise and could help increase transmission of communication calls such as whistles.

Recent studies, however, have argued that noise-induced frequency shifts may principally be explained as an epiphenomenon of the Lombard effect (reviewed in Brumm \& Zollinger, 2011). Where explicitly studied, the Lombard effect has been demonstrated in all nonhuman mammalian species (Hotchkin \& Parks, 2013), including several cetacean species (Holt et al., 2009; Parks et al., 2011; Scheifele et al., 2005). In several bird and mammal species, the Lombard effect is associated with a range of other changes in vocal output, including a rise in fundamental frequency (Dabelsteen, 1984; Hotchkin, Parks, \& Weiss, 2015; Nelson, 2000; Nemeth et al., 2013; Ritschard \& Brumm, 2011; Tressler \& Smotherman, 2009). Dolphins can readily adjust the amplitude of their calls (Au \& Benoit-Bird, 2003; Tyack, 1985). Thus a behavioural adaptation whereby dolphins attempt to increase their call amplitude above 
masking noise to minimize any reduction in whistle communication range might also explain the frequency shift we observed. Research devoted to understanding a possible connection between the Lombard effect and other noise-induced vocal modifications, including frequency shifts, has received minimal attention in the nonhuman field of communication research (Hotchkin \& Parks, 2013). As we could not measure whistle source levels, it was not possible for us to determine whether the shifts in frequency we observed were accompanied by amplitude modifications. Previous studies investigating the Lombard effect in cetaceans did not investigate concurrent changes in signal frequency (Holt et al., 2009; Scheifele et al., 2005) or failed to demonstrate a frequency shift associated with increased amplitude (Holt et al., 2015; Parks et al., 2011). However, as this research area is in its infancy, a possible coupling between the Lombard effect and other noise-induced vocal modifications in cetaceans warrants further investigation (Hotchkin \& Parks, 2013).

In relation to whistle frequency parameters, we can summarize our findings by saying that dolphins in Walvis Bay increase the frequency of some whistle parameters when boats are present, with some of the changes observed attributed to engine noise. However, we found a stronger effect with an increasing number of boats present (i.e. the RV versus RV plus one or more tour boats), which included times when tour boats were moving rather than stationary, indicating that several factors may contribute to enhance the observable effect. We cannot, however, argue whether our results are principally explained by animals shifting whistle frequency higher to reduce masking effects, as a by-product of increasing call amplitude above background noise, or a combination of these explanations which are not mutually exclusive. 
Prolonging call duration is another mechanism whereby animals may increase detection probability in elevated noise conditions (Brumm, Voss, Köllmer, \& Todt, 2004). Several delphinid species, including one population of bottlenose dolphins, have been found to increase call duration in relation to boat presence (Foote et al., 2004; Lesage et al., 1999; May-Collado \& Wartzok, 2008), while others have not (Buckstaff, 2004; Luís et al., 2014). We did not detect any influence of tour boat presence on either whistle duration or number of inflection points in Walvis Bay bottlenose dolphins. This might be explained by the fact that a substantial proportion of the whistle repertoire of the common bottlenose dolphin population in Walvis Bay includes signature whistles (Kriesell et al., 2014). Bottlenose dolphins commonly extend or reduce the duration of their signature whistles (Deecke \& Janik, 2006; Sayigh, Tyack, Wells, \& Scott, 1990), and this time warping relates to behavioural context (Esch, Sayigh, Blum, et al., 2009; Janik, Dehnhardt, \& Todt, 1994; this study). This may conceal any specific response to boat presence. As we detected a significant shift in whistle duration between different behavioural states, with whistles made during resting being the longest, we suggest that in this species, time warping is not used to increase communication distance or detection probability of whistles during noise, but may instead be used to convey motivational information, with shortened calls (and high repetition rates) more commonly used during states of greater emotional arousal (Esch, Sayigh, Blum, et al., 2009; Janik et al., 1994), and longer calls associated with times of rest. Shifting the whistle frequency upwards while maintaining other whistle parameters could be advantageous if it allows for the accurate transmission of identity or arousal information during times of elevated background noise.

Surface behaviour was strongly linked to variation in all whistle parameters measured, the most striking differentiation occurring between resting behaviour and behaviours associated 
with a higher state of emotional arousal such as socializing and surface feeding (Fig. 2). Previous studies have identified differences in the frequency and duration parameters of whistles relative to behavioural state (e.g. Azevedo et al., 2010; Díaz López, 2011; Hernandez et al., 2010; May-Collado, 2013). Several whistle types (Lilly, 1963; Rehn, Filatova, Durban, \& Foote, 2011) or call combinations incorporating whistles have also been linked to high states of emotional arousal (see Herzing, 2000 for a review). However, there are few studies comparable to ours that have investigated dolphin whistle parameters over a spectrum of behavioural states ranging from low arousal (e.g. resting) to high arousal (e.g. surface feeding and socializing). Drawing comparisons to our findings is therefore challenging and more relevant comparisons can be found with studies of terrestrial species (Briefer, 2012).

In general, the patterns identified across a range of mammalian species (Briefer, 2012) appear to hold true for the bottlenose dolphin population studied here, as we found an upward shift in most parameters of the fundamental frequency (start, end and minimum frequency) during behaviours associated with higher states of emotional arousal. Interestingly, maximum frequency did not fit this trend, as this parameter was higher during resting than the more aroused states, resulting in an increased frequency range used during resting. In addition, the duration of whistles, which was longest during resting and shortest during surface feeding and socializing, opposes the general but less consistent pattern in other species of longer call duration in states of greater arousal (Briefer, 2012). Our finding that inflection points decreased from lower to higher states of arousal also contradicts results from Esch, Sayigh, Blum, et al. (2009), who found that the number of loops in dolphin whistles increased during stressful circumstances. However, these differences may be attributed to differences between analysing only signature whistles (Esch, Sayigh, Blum, et al., 2009) and analysing the whole 
whistle repertoire (this study) or that arousal during different behavioural states and arousal due to stress induced by temporary capture are not entirely analogous. Another possible source of variance is that shifts in vocalization parameters can also be affected by the emotional valence of the context (Briefer, 2012; Soltis, Blowers, \& Savage, 2011), something that could not be controlled in our study but warrants further research.

When calves were present in a group, end and minimum frequency shifted downwards and whistle duration increased. The presence of calves may influence whistle parameters either directly through inclusion of calf whistles in the sample or indirectly by differences in the vocal production of groups containing calves, for example if females with calves produce their signature whistles more frequently than those without calves (Fripp \& Tyack, 2008). Our results indicate that a certain proportion of the whistles recorded from groups containing calves may have been produced by the calves themselves, as calf whistles can be significantly longer and lower frequency than adult whistles (Fripp \& Tyack, 2008), reflecting the pattern we identified in calf-present groups. However, other studies focusing on signature whistles have found that whistle duration (and number of inflection points) increases with age (Caldwell \& Caldwell, 1979; Caldwell et al., 1990). The differences in duration observed could therefore also be explained by increased rates of signature whistle production by adult animals, possibly mothers during separations from their offspring in the mother-calf groups (Mello \& Amundin, 2005; Sayigh et al., 1990; Smolker, Mann, \& Smuts, 1993). As in other studies (Hawkins \& Gartside, 2010), calf presence in this population is highly correlated with group size, with calves being present in larger groups (Kriesell et al., 2014). Consequently the influence of calf presence and group size on whistle parameters cannot easily be disentangled. Larger groups where individual separation distances could be greater may use lower frequency whistles of longer duration to enhance signal propagation (Janik, 2000). A 
significant interaction between calf presence and tour boat presence in the modelling output suggests that maximum frequency shifts upwards in the presence of tour boats, but only in groups where calves are absent. This result may be influenced by calf whistling behaviour. If calves have less control over their whistle outputs than adults (Caldwell \& Caldwell, 1979), they may not readily shift their whistle frequency in the presence of tour boats, which could lower the group average for this parameter. Although the reasoning for this interaction is less clear than for other results, it demonstrates that the influence of boat presence may be dependent on group composition.

We identified a short-term shift in whistle frequencies which is characteristic of the behavioural plasticity associated with bottlenose dolphins. However, over time such small changes may become longer lasting (Lusseau \& Bejder, 2007). Walvis Bay is characterized by a sandy/mud seabed type which contains several anoxic strata. In the absence of vessel activity, ambient noise levels are minimal (Elwen \& Gridley, n.d.), particularly in the mornings when biological sounds from fish and wind-generated abiotic noise are low. The marine tourism industry in Walvis Bay is well established (Leeney, 2014) and a long-term programme of coastal construction is planned in Walvis Bay over coming years which will substantially increase vessel traffic in the future (ARUP, 2013; Namport, 2013). Over time, changes in the ambient background noise caused by increased vessel traffic could result in long-term shifts in the frequency of whistles used. Such changes have been identified, for example, in birds (Luther \& Baptista, 2009) but also in cetacean species in response to longterm increase in anthropogenic noise levels (Foote et al., 2004; Parks et al., 2007) and should be closely monitored in Walvis Bay. The results of our study suggest that when feasible and safe to do so, reducing unnecessary underwater noise by switching boat engines off during 
encounters could lessen the overall impact of marine tourism on the bottlenose dolphin community in Walvis Bay.

\section{ACKNOWLEDGMENTS}

This publication is an output from the Namibian Dolphin Project. We are grateful to all the volunteers, students and research assistants who have helped collect these data. T.G. was funded during the initial stages of this work by a NERC PhD studentship, a University of St Andrews Russell Trust Award and later the University of Pretoria Vice Chancellor's postdoctoral fellowship. Post-doctoral fellowships from the University of Pretoria and Claude Leon Foundation provided assistance to S.E. Equipment and running costs were provided by Idea Wild Fund, Professor V. Janik and the Nedbank Go Green Fund. We thank Professor R. Millar and Professor M. Bester for support through the University of Pretoria Mammal Research Institute. We also thank T. Photopoulou for the statistical advice during this work and $\mathrm{EMBC}+$, the International Master of Science in Marine Biodiversity and Conservation Programme for financial contribution to the thesis and mobility cost of J.H. Research was conducted with permission from the Namibian Ministry of Fisheries and Marine Resources and we thank Dr J-P Roux for his support throughout our research activities.

\section{REFERENCES}

Amir, O. A., \& Jiddawi, N. S. (2001). Dolphin tourism and community participation in Kizimkazi village, Zanzibar. WIOMSA Book Series(1), 551-560.

Ansmann, I. C., Goold, J. C., Evans, P. G. H., Simmonds, M., \& Keith, S. G. (2007). Variation in the whistle characteristics of short-beaked common dolphins, Delphinus delphis, at two locations around the British Isles. Journal of the Marine Biological Association of the United Kingdom, 87(1), 19-26. 
Arcangeli, A., \& Crosti, R. (2009). The short-term impact of dolphin-watching on the behaviour of bottlenose dolphins (Tursiops truncatus) in western Australia. Journal of Marine Animals and Their Ecology, 2(1), 3-9.

ARUP. (2013). The Walvis Bay SADC Gateway Port Development: Consolidated report on pre-feasibility studies, May 2013.

Au, W. W. L., \& Benoit-Bird, K. J. (2003). Automatic gain control in the echolocation system of dolphins. Nature, 423(6942), 861-863.

Azevedo, A. F., Flach, L., Bisi, T. L., Andrade, L. G., Dorneles, P. R., \& Lailson-Brito, J. (2010). Whistles emitted by Atlantic spotted dolphins (Stenella frontalis) in southeastern Brazil. Journal of the Acoustical Society of America, 127(4), 2646-2651.

Bejder, L., Samuels, A., Whitehead, H., Gales, N., Mann, J., Conner, R. N., et al. (2006). Decline in relative abundance of bottlenose dolphins exposed to long-term disturbance. Conservation Biology, 20(6), 1791-1798.

Berggren, P., Amir, O. A., Guissamulo, A., Jiddawi, N. S., Ngazy, Z., Stensland, E., et al. (2007). Sustainable dolphin tourism in East Africa. MASMA Technical Report. WIOMSA Book Series No. 7. Western Indian Ocean Marine Science Association (WIOMSA), Zanzibar.

Best, P. B. (2007). Common bottlenose dolphin, Tursiops truncatus. In D. v. d. Horst (Ed.), Whales and dolphins of the Southern African Subregion (pp. 174-180). Cambridge, U.K.: Cambridge University Press.

Briefer, E. F. (2012). Vocal expression of emotions in mammals: mechanisms of production and evidence. Journal of Zoology, 288(1), 1-20.

Brumm, H., \& Slabbekoorn, H. (2005). Acoustic communication in noise. Advances in the Study of Behavior, 35, 151-209. 
Brumm, H., Voss, K., Köllmer, I., \& Todt, D. (2004). Acoustic communication in noise: regulation of call characteristics in a New World monkey. Journal of Experimental Biology, 207(3), 443-448.

Brumm, H., \& Zollinger, S. A. (2011). The evolution of the Lombard effect: 100 years of psychoacoustic research. Behaviour, 148(11-13), 1173-1198.

Buckstaff, K. C. (2004). Effects of watercraft noise on the acoustic behavior of bottlenose dolphins, Tursiops truncatus, in Sarasota Bay, Florida. Marine Mammal Science, 20(4), 709-725.

Caldwell, M. C., \& Caldwell, D. K. (1979). The whistle of the Atlantic bottlenosed dolphin (Tursiops truncatus)-ontogeny. In H. E. Winn (Ed.), Behaviour of marine animals (Vol. 3, pp. 369-401). New York, NY: Plenum Press.

Caldwell, M. C., Caldwell, D. K., \& Tyack, P. L. (1990). Review of the signature-whistle hypothesis for the Atlantic bottlenose dolphin. In S. Leatherwood \& R. R. Reeves (Eds.), The Bottlenose Dolphin (pp. 199-234). San Diego, CA: Academic Press.

Christiansen, F., Lusseau, D., Stensland, E., \& Berggren, P. (2010). Effects of tourist boats on the behaviour of Indo-Pacific bottlenose dolphins of the South coast of Zanzibar. Endangered Species Research, 11, 91-99.

Clark, C. W., Ellison, W. T., Southall, B. L., Hatch, L., Van Parijs, S. M., Frankel, A., et al. (2009). Acoustic masking in marine ecosystems: intuitions, analysis, and implication. Marine Ecology Progress Series, 395, 201-222.

Cook, M. L. H., Sayigh, L. S., Blum, J. E., \& Wells, R. S. (2004). Signature-whistle production in undisturbed free-ranging bottlenose dolphins (Tursiops truncatus). Proceedings of the Royal Society of London Series B-Biological Sciences, 271(1543), 1043-1049.

Crawley, M. J. (2007). The R book. Chichester, U.K.: Wiley. 
Dabelsteen, T. (1984). An Analysis of the Full Song of the Blackbird Turdus merula with Respect to Message Coding and Adaptations for Acoustic Communication. Ornis Scandinavica, 15(4), 227-239.

Deecke, V. B., \& Janik, V. M. (2006). Automated categorization of bioacoustic signals: Avoiding perceptual pitfalls. Journal of the Acoustical Society of America, 119(1), 645-653.

Díaz López, B. (2011). Whistle characteristics in free-ranging bottlenose dolphins (Tursiops truncatus) in the Mediterranean Sea: influence of behaviour. Mammalian Biology, 76, 180-189.

Dunlop, R. A., Cato, D. H., \& Noad, M. J. (2010). Your attention please: increaseing ambient noise levels elicits change in communication behaviour in humpback whales (Megaptera novaeangliae). Proceedings of the Royal Society B-Biological Sciences, $277,2521-2529$.

Ellison, W. T., Southall, B. L., Clarke, C. W., \& Frankel, A. S. (2011). A New Context-Based Approach to Assess Marine Mammal Behavioral Responses to Anthropogenic Sounds. Conservation Biology, 26(1), 21-28.

Elwen, S.H., Gridley, T. (n.d.) [ambient noise recordings in Walvis Bay] unpublished raw data.

Elwen, S. H., Snyman, L., \& Leeney, R. H. (2011). Report of the Nambian Dolphin Project 2010: Ecology and consevation of coastal dolphins in Namibia. Walvis Bay, Namibia: National Marine Information and Resource Centre.

Esch, H. C., Sayigh, L. S., Blum, J. E., \& Wells, R. S. (2009). Whistles as potential indicators of stress in bottlenose dolphins (Tursiops truncatus). Journal of Mammalogy, 90(3), 638-650. 
Esch, H. C., Sayigh, L. S., \& Wells, R. S. (2009). Quantifying parameters of bottlenose dolphin signature whistles. Marine Mammal Science, 25(4), 976-986.

Findlay, K. P., Best, P. B., Ross, G. J. B., \& Cockcroft, V. G. (1992). The distribution of small odontocete cetaceans off the coasts of South Africa and Namibia. South African Journal of Marine Science, 12, 237-270.

Foote, A. D., \& Nystuen, J. A. (2008). Variation in call pitch among killer whale ecotypes. Journal of the Acoustical Society of America, 123(3), 1747-1752.

Foote, A. D., Osborne, R. W., \& Hoelzel, A. R. (2004). Environment-Whale-call response to masking boat noise. Nature, 428(6986), 910-910.

Fripp, D., \& Tyack, P. (2008). Postpartum whistle production in bottlenose dolphins. Marine Mammal Science, 24(3), 479-502.

Gridley, T., Berggren, P., Cockcroft, V. G., \& Janik, V. M. (2012). Whistle vocalizations of Indo-Pacific bottlenose dolphins (Tursiops aduncus) inhabiting the south-west Indian Ocean. Journal of the Acoustical Society of America, 132(6), 4032-4040.

Gridley, T., Nastasi, A., Kriesell, H. J., \& Elwen, S. H. (2015). The acoustic repertoire of wild common bottlenose dolphins (Tursiops truncatus) in Walvis Bay, Namibia. Bioacoustics, 24(2), 153-174.

Hage, S. R., Jiang, T., Berquist, S. W., Feng, J., \& Metzner, W. (2013). Ambient noise induces independent shifts in call frequency and amplitude within the Lombard effect in echolocating bats. Proceedings of the National Academy of Sciences, 110(10), 4063-4068.

Hastie, G. D., Wilson, B., Tufft, L. H., \& Thompson, P. M. (2003). Bottlenose dolphins increase breathing synchrony in response to boat traffic. Marine Mammal Science, 19(1), 74-84. 
Hawkins, E. R., \& Gartside, D. F. (2010). Whistle emissions of Indo-Pacific bottlenose dolphins (Tursiops aduncus) differ with group composition and surface behaviors. Journal of the Acoustical Society of America, 127(4), 2652-2663.

Henderson, E. E., Hildebrand, J. A., \& Smith, M. H. (2011). Classification of behavior using vocalizations of Pacific white-sided dolphins (Lagenorhynchus obliquidens). Jounal of the Acoustical Society of America, 130(1), 557-567.

Henderson, E. E., Hildebrand, J. A., Smith, M. H., \& Falcone, E. A. (2012). The behavioral context of common dolphin (Delphinus sp.) vocalizations. Marine Mammal Science, $28(3), 439-460$.

Hernandez, E. N., Solangi, M., \& Kuczaj, S. A., II. (2010). Time and frequency parameters of bottlenose dolphin whistles as predictors of surface behavior in the Mississippi Sound. Journal of the Acoustical Society of America, 127(5), 3232-3238.

Herzing, D. L. (2000). Acoustics and social behavior of wild dolphins: implications for a sound society Hearing by whales and dolphins (pp. 225-272). Springer Handbook of Auditory Research. http://link.springer.com/bookseries/2506

Holt, M. M., Noren, D. P., Dunkin, R. C., \& Williams, T. M. (2015). Vocal performance affects metabolic rate in dolphins: implications for animals communicating in noisy environments. The Journal of Experimental Biology, 218(11), 1647-1654.

Holt, M. M., Noren, D. P., Veirs, V., Emmons, C. K., \& Veirs, S. (2009). Speaking up: Killer whales (Orcinus orca) increase their call amplitude in response to vessel noise. Journal of the Acoustical Society of America, 125(1), EL27-EL32.

Hotchkin, C., \& Parks, S. (2013). The Lombard effect and other noise-induced vocal modifications: insight from mammalian communication systems. Biological Reviews, 88(4), 809-824. 
Hotchkin, C., Parks, S. E., \& Weiss, D. J. (2015). Noise-Induced Frequency Modifications of Tamarin Vocalizations: Implications for Noise Compensation in Nonhuman Primates. PLoS ONE, 10(6), e0130211.

Hoyt, E. (2001). Whale watching 2001: Worldwide tourism numbers, expenditures, and expanding socioeconomic benefits. Yarmouth Port, MA, USA.

IFAW. (1997). Report of the international workshop on the Educational values of whale watching: Provincetown, Massachusetts, USA, 8th May-11th May, 1997.

Crowborough: International Fund for Animal Welfare.

Indurkhya, X. (2012). Behavioural responses to tour boats and the role of social relationships in a population of bottlenose dolphins (Tursiops truncatus) in Walvis Bay, Namibia. (Unpublished MSc. Thesis). Trento, Italy: University of Trento.

IWC. (2014). Annual report of the International Whaling Commission Aug 2012-Aug 2013. Cambridge, U.K.: International Whaling Commission.

Janik, V. M. (2000). Source levels and the estimated active space of bottlenose dolphin (Tursiops truncatus) whistles in the Moray Firth, Scotland. Journal of Comparative Physiology a-Sensory Neural and Behavioral Physiology, 186(7-8), 673-680.

Janik, V. M., Dehnhardt, G., \& Todt, D. (1994). Signature whistle variations in a bottlenosed dolphin, Tursiops truncatus. Behavioral Ecology and Sociobiology, 35(4), 243-248.

Janik, V. M., King, S. L., Sayigh, L. S., \& Wells, R. S. (2013). Identifying signature whistles from recordings of groups of unrestrained bottlenose dolphins (Tursiops truncatus). Marine Mammal Science, 29, 109-122.

Janik, V. M., Sayigh, L. S., \& Wells, R. S. (2006). Signature whistle shape conveys identity information to bottlenose dolphins. Proceedings of the National Academy of Sciences of the United States of America, 103(21), 8293-8297. 
Janik, V. M., \& Slater, P. J. B. (1997). Vocal learning in mammals. Advances in the study of behavior, 26, 59-99.

Janik, V. M., \& Slater, P. J. B. (1998). Context-specific use suggests that bottlenose dolphin signature whistles are cohesion calls. Animal Behaviour, 56, 829-838.

Jensen, F. H., Bejder, L., Wahlberg, M., Aguilar Soto, N., Johnson, M., \& Madsen, P. T. (2009). Vessel noise effects on delphinid communication. Marine Ecology Progress Series, 395, 161-175.

Jones, G. J., \& Sayigh, L. S. (2002). Geographic variation in rates of vocal production of free-ranging bottlenose dolphins. Marine Mammal Science, 18(2), 374-393.

King, S. L., \& Janik, V. M. (2013). Bottlenose dolphins can use learned vocal labels to address each other. Proceedings of the National Academy of Sciences of the United States of America, 110(32), 13216-13221.

King, S. L., \& Janik, V. M. (2015). Come dine with me: food-associated social signalling in wild bottlenose dolphins (Tursiops truncatus). Animal Cognition, 18(4), 969-974.

King, S. L., Sayigh, L. S., Wells, R. S., Fellner, W., \& Janik, V. M. (2013). Vocal copying of individually distinctive signature whistles in bottlenose dolphins. Proceedings of the Royal Society B: Biological Sciences, 280(1757).

Kriesell, H., Elwen, S. H., Nastasi, A., \& Gridley, T. (2014). Identification and characteristics of signature whistles in wild bottlenose dolphins (Tursiops truncatus) from Namibia. PLoS ONE, 9(9), e106317.

La Manna, G., Manghi, M., Pavan, G., Lo Mascolo, F., \& Sarà, G. (2013). Behavioural strategy of common bottlenose dolphins (Tursiops truncatus) in response to different kinds of boats in the waters of Lampedusa Island (Italy). Aquatic Conservation: Marine and Freshwater Ecosystems, 23(5), 745-757. 
Langsrud, Ø. (2003). ANOVA for unbalanced data: Use Type II instead of Type III sums of squares. Statistics and Computing, 13(2), 163-167.

Leeney, R. H. (2014). Towards Sustainability of Marine Wildlife-Watching Tourism in Namibia. Journal of the Namibian Scientific Society, 62, 9-33.

Lemon, M., Lynch, T. P., Cato, D. H., \& Harcourt, R. G. (2006). Response of travelling bottlenose dolphins (Tursiops aduncus) to experimental approaches by a powerboat in Jervis Bay, New South Wales, Australia. Biological Conservation, 127(4), 363-372.

Lesage, V., Barrette, C., Kingsley, M. C. S., \& Sjare, B. (1999). The effect of vessel noise on the vocal behavior of Belugas in the St. Lawrence River estuary, Canada. Marine Mammal Science, 15(1), 65-84.

Lilly, J. C. (1963). Distress call of the bottlenose dolphin: stimuli and evoked behavioral responses. Science, 139(3550), 116-118.

Lilly, J. C., \& Miller, A. M. (1961). Sounds emitted by the bottlenose dolphin. Science, 133(3465), 1689-1693.

Lombard, E. (1911). Le signe de l'elevation de la voix. Annales Maladies Oreille, Larynx, Nez, Pharynx, 37(101-119).

Luís, A. R., Couchinho, M. N., \& dos Santos, M. E. (2014). Changes in the acoustic behavior of resident bottlenose dolphins near operating vessels. Marine Mammal Science, $30(4), 1417-1426$.

Lusseau, D. (2003a). Effects of tour boats on the behavior of bottlenose dolphins: using Markov chains to model anthropogenic impacts. Conservation Biology, 17(6), 17851793.

Lusseau, D. (2003b). Male and female bottlenose dolphins Tursiops spp. have different strategies to avoid interactions with tour boats in Doubtful Sound, New Zealand. Marine Ecology Progress Series, 257, 267-274. 
Lusseau, D., \& Bejder, L. (2007). The Long-term Consequences of Short-term Responses to Disturbance Experiences from Whalewatching Impact Assessment. International Journal of Comparative Psychology, 20(2), 228-236.

Luther, D., \& Baptista, L. (2009). Urban noise and the cultural evolution of bird songs. Proceedings of the Royal Society B: Biological Sciences, 277(1680), 469-473.

Mann, J. (1999). Behavioural sampling methods for cetaceans: A review and critique. Marine Mammal Science, 15(1), 102-122.

May-Collado, L. J. (2013). Guyana dolphins (Sotalia guianensis) from Costa Rica emit whistles that vary with surface behaviors. The Journal of the Acoustical Society of America, 134(4), EL359-EL365.

May-Collado, L. J., \& Quiñones-Lebrón, S. G. (2014). Dolphin changes in whistle structure with watercraft activity depends on their behavioral state. The Journal of the Acoustical Society of America, 135(4), EL193-EL198.

May-Collado, L. J., \& Wartzok, D. (2008). A comparison of bottlenose dolphin whistles in the Atlantic Ocean: factors promoting whistle variation. Journal of Mammalogy, 89(5), 1229-1240.

Mello, I., \& Amundin, M. (2005). Whistle production pre- and post-partum in bottlenose dolphins (Tursiops truncatus) in human care. Aquatic Mammals, 31(2), 169-175.

Morisaka, T., Shinohara, M., Nakahara, F., \& Akamatsu, T. (2005). Effects of ambient noise on the whistles of Indo-Pacific bottlenose dolphin populations. Journal of Mammalogy, 86(3), 541-546.

Mossbridge, J. A., Shedd, J. G., \& Thomas, J. A. (1999). An "acoustic niche" for antarctic killer whale and leopard seal sounds. Marine Mammal Science, 15(4), 1351-1357. Namport. (2013). Consolidated report on the pre-feasibility studies. Walvis Bay: Namibian Ports Authority. 
Nelson, B. S. (2000). Avian dependence on sound pressure level as an auditory distance cue. Animal Behaviour, 59(1), 57-67.

Nemeth, E., Pieretti, N., Zollinger, S. A., Geberzahn, N., Partecke, J., Miranda, A. C., et al. (2013). Bird song and anthropogenic noise: vocal constraints may explain why birds sing higher-frequency songs in cities. Proceedings of the Royal Society B: Biological Sciences, 280(1754), 20122798-20122798.

O’Connor, S., Campbell, R., Cortez, H., \& Knowles, T. (2009). Whale Watching Worldwide: tourism numbers, expenditures and expanding economic benefits, a special report from the International Fund for Animal Welfare. Yarmouth MA, USA, prepared by Economists at Large.

Parks, S. E., Clark, C. W., \& Tyack, P. L. (2007). Short- and long-term changes in right whale calling behavior: the potential effects of noise on acoustic communication. Journal of the Acoustical Society of America, 122(6), 3725-3731.

Parks, S. E., Johnson, M., Nowacek, D., \& Tyack, P. (2011). Individual right whales call louder in increased environmental noise. Biology Letters, 7, 33-35.

Parsons, E. C. M. (2012). The Negative Impacts of Whale-Watching. Journal of Marine Biology, 2012, 9.

Pirotta, E., Merchant, N. D., Thompson, P. M., Barton, T. R., \& Lusseau, D. (2015). Quantifying the effect of boat disturbance on bottlenose dolphin foraging activity. Biological Conservation, 181, 82-89.

Pirotta, E., Milor, R., Quick, N., Moretti, D., Di Marzio, N., Tyack, P., et al. (2012). Vessel noise affects beaked whale behavior: results of a dedicated acoustic response study. PLoS One, 7(8), e42535. 
Quick, N. J., \& Janik, V. M. (2008). Whistle rates of wild bottlenose dolphins (Tursiops truncatus): influences of group size and behavior. Journal of Comparative Psychology, 122(3), 305-311.

Quick, N. J., \& Janik, V. M. (2012). Bottlenose dolphins exchange signature whistles when meeting at sea. Proceedings of the Royal Society B, 279, 2539-2545.

Radford, A. N., Kerridge, E., \& Simpson, S. D. (2014). Acoustic communication in a noisy world: can fish compete with anthropogenic noise? Behavioral Ecology, 25(5), 10221030.

Rako, N., Fortuna, C. M., Holcer, D., Mackelworth, P., Nimak-Wood, M., Pleslić, G., et al. (2013). Leisure boating noise as a trigger for the displacement of the bottlenose dolphins of the Cres-Lošinj archipelago (northern Adriatic Sea, Croatia). Marine Pollution Bulletin, 68(1-2), 77-84.

Rehn, N., Filatova, O. A., Durban, J. D., \& Foote, A. D. (2011). Cross-cultural and crossecotype production of a killer whale 'excitement' call suggests universality. Naturwissenschaften, 98(1-6).

Ritschard, M., \& Brumm, H. (2011). Effects of vocal learning, phonetics and inheritance on song amplitude in zebra finches. Animal Behaviour, 82(6), 1415-1422.

Rolland, R. M., Parks, S. E., Hunt, K. E., Castellote, M., Corkeron, P. J., Nowacek, D. P., et al. (2012). Evidence that ship noise increases stress in right whales. Proceedings of the Royal Society B, 279(1737), 2363-2368.

Romano, T. A., Keogh, M. J., Kelly, C., Feng, P., Berk, L., Schlundt, C. E., et al. (2004). Anthropogenic sound and marine mammal health: measures of the nervous and immune systems before and after intense sound exposure. Canadian Journal of Fisheries and Aquatic Sciences, 61, 1124-1134. 
Sayigh, L. S., Tyack, P. L., Wells, R. S., \& Scott, M. D. (1990). Signature whistles of freeranging bottlenose dolphins Tursiops truncatus: stability and mother-offspring comparisons. Behavioral Ecology and Sociobiology, 26(4), 247-260.

Scarpaci, C., Bigger, S. W., Corkeron, P. J., \& Nugegoda, D. (2000). Bottlenose dolphins (Tursiops truncatus) increase whistling in the presence of 'swim-with dolphin' tour operators. Journal of Cetacean Research and Management, 2(3), 183-185.

Scheifele, P. M., Andrew, S., Cooper, R. A., Darre, M., Musiek, F. E., \& Max, L. (2005). Indication of a Lombard vocal response in the St. Lawrence River beluga. Journal of the Acoustical Society of America, 117(3), 1486-1492.

Schultz, K. W., \& Corkeron, P. J. (1994). Interspecific differences in whistles produced by inshore dolphins in Moreton Bay, Queensland, Australia. Canadian Journal of Zoology, 72(6), 1061-1068.

Simard, P., Lace, N., Gowans, S., Quintana-Rizzo, E., Kuczaj II, S. A., Wells, R. S., et al. (2011). Low frequency narrow-band calls in bottlenose dolphins (Tursiops truncatus): signal properties, function, and conservation implications. Journal of the Acoustical Society of America, 130(5), 3068-3076.

Smolker, R. A., Mann, J., \& Smuts, B. B. (1993). Use of signature whistles during separations and reunions by wild bottlenose dolphin mothers and infants. Behavioral Ecology and Sociobiology, 33(6), 393-402.

Soltis, J., Blowers, T. E., \& Savage, A. (2011). Measuring positive and negative affect in the voiced sounds of African elephants (Loxodonta africana). The Journal of the Acoustical Society of America, 129(2), 1059-1066.

Steckenreuter, A., Möller, L., \& Harcourt, R. G. (2012). How does Australia’s largest dolphin-watching industry affect the behaviour of a small and resident population of Indo-Pacific bottlenose dolphins? . Journal of Environmental Management, 97, 14-21. 
Stensland, E., \& Berggren, P. (2007). Behavioural changes in female Indo-Pacific bottlenose dolphins in response to boat-based tourism. Marine Ecology-Progress Series, 332, 225-234.

Tressler, J., \& Smotherman, M. S. (2009). Context-dependent effects of noise on echolocation pulse characteristics in free-tailed bats. Journal of Comparative Physiology A, 195(10), 923-934.

Tyack, P. L. (1985). An optical telemetry device to identify which dolphin produces a sound. Journal of the Acoustical Society of America, 78(5), 1892-1895.

Tyack, P. L. (1986). Whistle repertoires of two bottlenosed dolphins, Tursiops truncatus: mimicry or signature whistles? Behavioral Ecology and Sociobiology, 18, 251-257.

van der Woude, S. E. (2009). Bottlenose dolphins (Tursiops truncatus) moan as low in frequency as baleen whales. Journal of the Acoustical Society of America, 126(3), $1552-1562$.

Watwood, S. L., Owen, E. C. G., Tyack, P. L., \& Wells, R. S. (2005). Signature whistle use by temporarily restrained and free-swimming bottlenose dolphins, Tursiops truncatus. Animal Behaviour, 69, 1373-1386.

Weilgart, L. S. (2007). A brief review of known effects of noise on marine mammals. International Journal of Comparative Psychology, 20, 159-168.

Williams, R., Lusseau, D., \& Hammond, P. S. (2006). Estimating relative energetic costs of human disturbance to killer whales (Orcinus orca). Biological Conservation, 133, 301-311. 